\title{
Malignant gliomas occurring in identical twins
}

\author{
B. FAIRBURN AND H. URICH
}

\author{
From Oldchurch Hospital, Romford, Essex, and The London Hospital, Whitechapel, London
}

SUMMARY The occurrence of malignant gliomas in a pair of identical twins is reported. One, in the् posterior fossa, presented in the third year of life, the other, in the left cerebral hemisphere, in the $\frac{\overline{0}}{\overline{\bar{D}}}$. eighth. Both ran a rapidly progressive course and died within a few months of the onset of symp- $-\frac{\bar{\sigma}}{\square}$ toms. The histological structure of the gliomas was similar and both tumours consisted of astrocytic尺 and oligodendroglial parts. Review of the literature revealed only two pairs of histologically provenes gliomas occurring in identical twins. The number of cases reported is too small for any valid con- $\overrightarrow{0}$ clusions on possible genetic mechanisms.

Genetic factors are unlikely to play a major part in the aetiology of gliomas other than within the context of specific hereditary syndromes such as neurofibromatosis. Yet the occasional occurrence of familial tumours demands a critical evaluation of possible genetic and environmental influences. The study of concordance in twins would throw some light on this problem, but the amount of published data is inadequate for analysis. We, therefore, wish to record a further instance of occurrence of histologically similar gliomas in identical twins, in the hope of stimulating further investigations.

\section{CASE REPORTS}

These twin boys were born on 6 April 1962, after a normal delivery. They were said to have had a common placenta. The father was aged 27, and the mother 26 years. There were no other children. The parents had been healthy and there was no consanguinity. The pregnancy had been normal and there was no exposure to $x$-rays or any significant illness. The boys were very alike both in appearance and personality, and they were always regarded by everyone as identical twins. Apart from childish ailments both boys were well until they developed their cerebral tumours.

TWIN 1 (S.W., London Hospital No. 272226) In March 1965 , at the age of 2 years and 11 months, this boy over the course of a month developed unsteadiness of gait which became progressively more severe until he had to revert to crawling. He was also noticed to have difficulty in controlling the use of his left hand. Ten days before his admission to hospital on 18 May 1965, he began to vomit in the mornings. On examination he was irritable and fretful. His fundi showed bilateral early papilloedema. He had ataxia of the left limbs and bilateral extensor plantar responses. Skull radiography showed suture diastasis.
Ventriculography on 26 May 1965 showed marked hydro.0 cephalus due to the presence of a left cerebellar tumour- $\omega$ A Torkildsen's operation (ventriculo-cisternostomy) was carried out the same day. There was little improvement - -

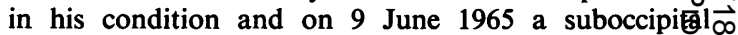
exploration with partial removal of an infiltrating tumoü, 응 occupying the vermis and the left cerebellar hemisphefe was carried out. Biopsy of the tumour showed a malignamt neoplasm consisting of uniformly distributed small ce with round, darkly staining nuclei. It was diagnosed, $\mathbb{D}$ erroneously, as it turned out, as a medulloblastoma. 迎要 was given a course of radiotherapy to the skull and spine. He remained drowsy, apathetic, and incontinent several weeks after operation but then began to improve slowly. When eventually discharged home on 14 January.1966, he was speaking a few words and walking with assistance.

He was readmitted on 16 March 1966 with a two weeks' history of recurrence of ataxia, vomiting, and irritability. His decompression was bulging and he again had marked $\stackrel{\circ}{\varnothing}$

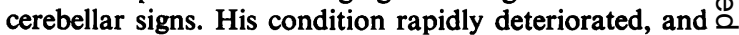
he died in coma on 22 March 1966. The total duration of $\overrightarrow{\overrightarrow{0}}$ his illness was 12 months.

TWIN 2 (K.W. Oldchurch Hospital No. 213072) On 12类 October 1969, at the age of $7 \frac{1}{2}$ years, this boy suddenly developed involuntary twitching of the right side of his mouth. This was followed by a generalized convulsion 0 with loss of consciousness for half an hour. On $31 \div$ October 1969, he complained of left-sided headache, and 3 . developed weakness of his right hand lasting for a few $\delta$ minutes. Over the next few days he complained of inter- 3 mittent headaches and had two focal epileptic attacks 0 affecting the right arm. On admission to hospital on 11 궁 November 1969, he was asymptomatic and showed no $\frac{D}{2}$ abnormal physical signs. Electroencephalogram, brain scan, and left carotid angiography suggested the presence $N$ of a small left parietal tumour. Taking into account the $\sigma$ excellent clinical condition of the boy, the probable nature $N$ of the lesion and its situation in the dominant parietal 718 
lobe, no surgical treatment was advised at that time and he was discharged home on anti-convulsant drugs.

He was readmitted on 2 January 1970 with a week's history of weakness of the right hand and dragging of the right leg. He was noted to be drowsy and to have severe bilateral papilloedema and a mild right hemiparesis. On the day of his admission, the left carotid angiogram was repeated. He was found to have a very large left parietal tumour. A left parietal burr-hole was made the same evening. At a depth of $3 \mathrm{~cm}$ a cystic cavity was entered from which $20 \mathrm{ml}$. of clear yellow fluid were aspirated. A needle biopsy of solid tumour deep to the cyst was obtained at the same time. It showed a small-cell malignant tumour similar to that found in his twin brother.

After this procedure his condition improved temporarily and his right hemiparesis cleared up. After discussion with the parents no surgical or radiotherapeutic treatment was undertaken. With the help of oral steroids he remained well until the beginning of March 1970 when he went rapidly downhill in the course of a few days and died in coma on 13 March 1970. The total duration of his illness was five months.

\section{PATHOLOGY}

CASE 1 (L.H. P.M. 93/66) Macroscopic appearances The cerebral hemispheres were obviously hydrocephalic with moderate symmetrical dilatation of the lateral ventricles and marked dilatation of the third ventricle. The brain-stem was asymmetrical with slight expansion of the left middle cerebellar peduncle and an irregular swelling of the left half of the medulla oblongata. Sections showed this to be due to a tumour $(3.5 \times 3.5 \times 2.5 \mathrm{~cm})$ occupying the white matter of the left cerebellar hemisphere ventral to the dentate nucleus, the adjacent brachium pontis, the restiform body, and the dorsolateral part of the medulla (Fig. 1). The tumour reached the surface of the dilated and displaced fourth ventricle at one point. The cut surface of the tumour was soft, pinkish-grey, and mottled with haemorrhages in its upper part. It gradually changed in texture and appearance towards the lower end which was firm, white, and homogeneous. There was no evidence of dissemination of the tumour through the subarachnoid space of the brain or spinal cord.

Histology Microscopically the tumour consisted of two distinct parts. That corresponding to the soft, greyish-pink areas was composed predominantly of small round cells with dark nuclei and indistinct cytoplasm which in some cells formed clear, unstained haloes round the nuclei (Fig. 2). There was considerable variation in size of the nuclei and in some areas giant cells with multiple or bizarre nuclei were abundant. Mitotic figures, some of them atypical, were frequent. The tumour was highly vascular and contained a rich network of regularly arranged capillaries. Haemorrhages of various sizes were scattered through the tumour. Some calcification was seen at the edges of the small celled areas. The appearances of this part were those of malignant oligodendroglioma.

The white, solid part of the tumour consisted of larger cells with more loosely structured nuclei and abundant pink cytoplasm. They showed considerable variation in size and shape. In some areas round or polygonal cells predominated with single or multiple nuclei arranged peripherally. Others were composed of bands or shoals of long spindle cells with elongated, rod-shaped nuclei (Fig. 3). Scattered among both type of cells were bizarre giant cells of monstrous size with a considerable variety of nuclear patterns. Most of them were mononuclear with either a spherical or irregularly lobed nucleus. The coarse

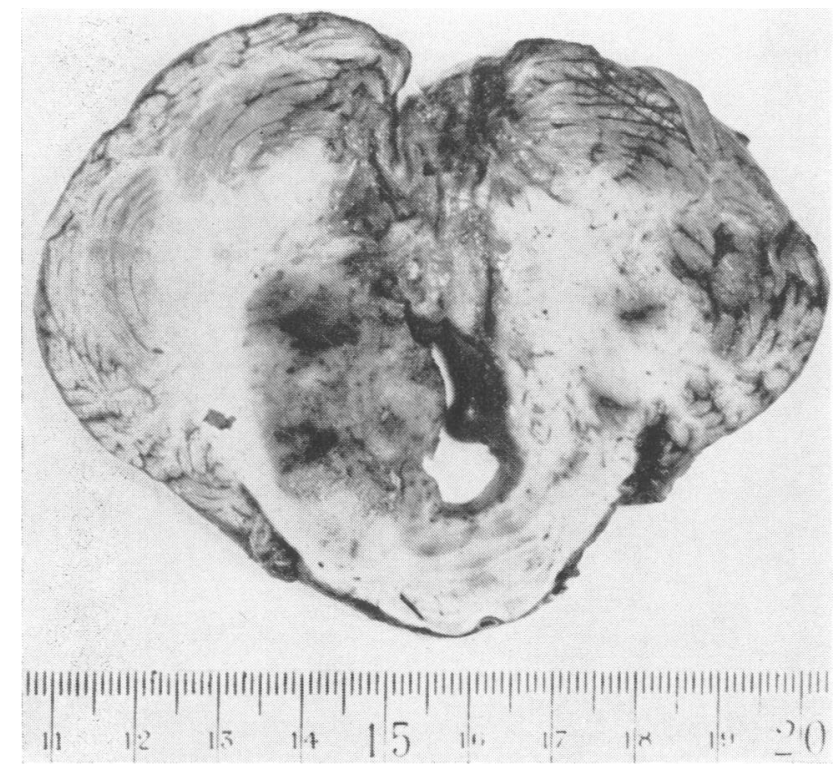

FIG. 1. Case 1. Transverse section through brain-stem and cerebellum showing tumour in left cerebellar hemisphere and brachium pontis. 


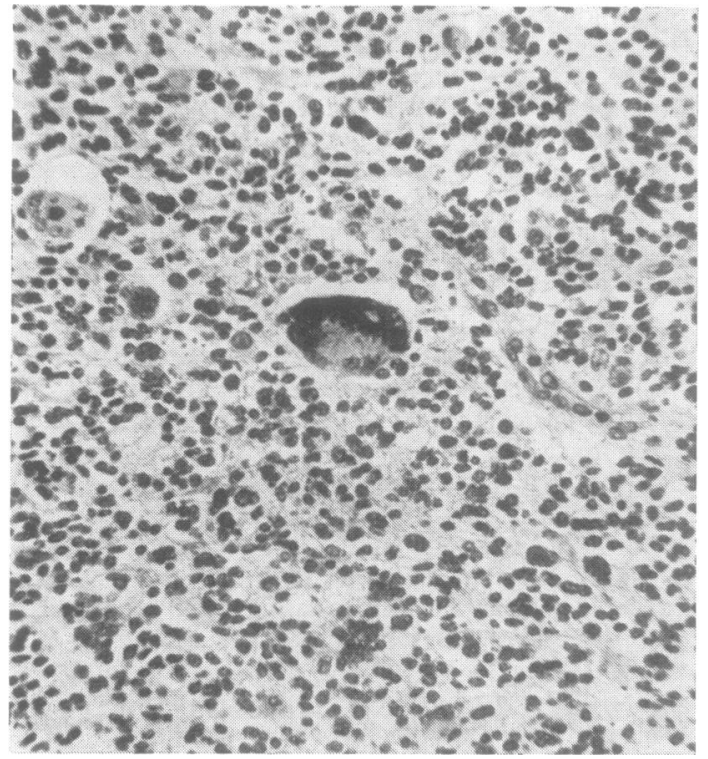

FIG. 2. Case 1. Small-celled part of the tumour with scattered giant cells. $H$ and $E, \times 240$.

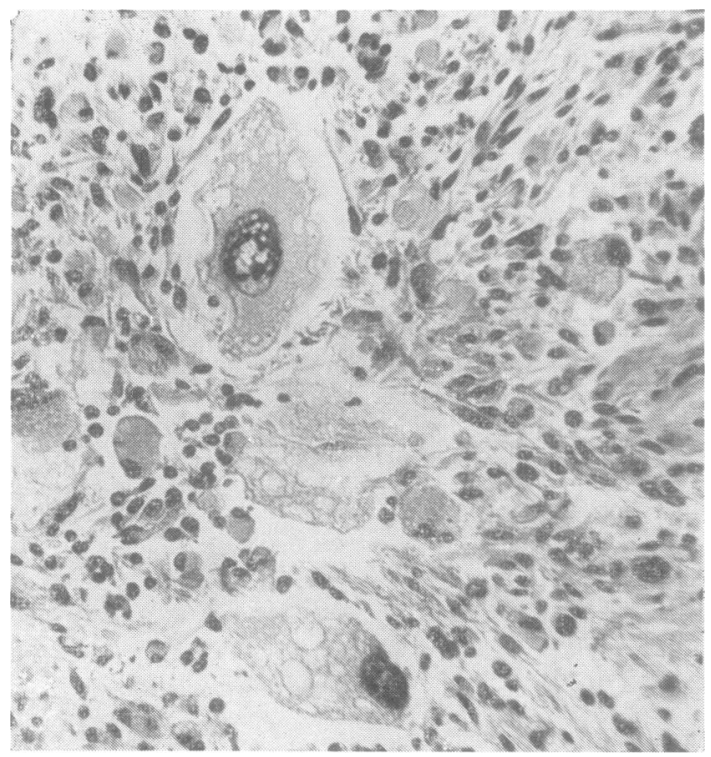

FIG. 3. Case 1. Large-celled part of tumour, consisting mainly of round or polygonal cells with numerous monster cells; groups of spindle cells also present. $H$ and $E, \times 240$. nuclear chromatin was distributed peripherally, the centre being occupied by a prominent nucleolus. Their cytoplasm was either homogeneous, pale pink, or finely vacuolated. Mitotic figures were abundant in all types of cells. No glial fibres could be visualized by special stains. This part of the tumour, which was probably astrocytic in origin, was sparsely vascular and free from haemorrhages.

The boundary between the two types of tumour was not clear-cut and both types of cell intermingled freely in a broad transition zone.

CASE 2 (L.H. P.M. No. 291/69) Macroscopic appearances The brain was asymmetrical with obvious expansion of the left hemisphere particularly in the posterior frontal, central, and inferior parietal regions. The left hippocampal gyrus was herniated over the edge of the tentorium. Coronal sections revealed a large tumour $(9 \times 6 \times 6 \mathrm{~cm})$ occupying the white matter of the posterior end of the third frontal convolution and of most of the parietal lobe (Fig. 4). It was separated from the lateral ventricle by a thin layer of preserved brain tissue, but it extended to the external surface in the inferior parietal lobule. The cut surface of the tumour showed a variegated appearance, the anterior end being white and homogeneous, the centre necrotic and haemorrhagic, the posterior end soft, greyish and stippled with small haemorrhages.

The tumour displaced the mid-line structures to the $\infty$ right and compressed the left lateral ventricle. The righn hemisphere, the brain-stem, and the cerebellum were normal.

HISTOLOGY This tumour also consisted of an oligoden droglial and an astrocytic part, the former comprising the bulk of the tumour, the latter forming its anterior end The oligodendroglial part consisted in some areas of

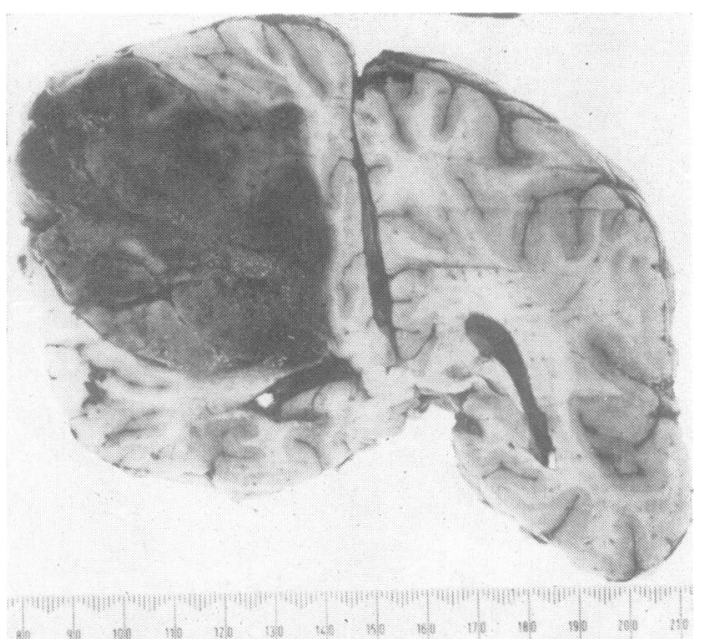

FIG. 4. Case 2. Coronal section through cerebral hemispheres at level of splenium showing left parietal tumour. 
typical small round cells, in others of somewhat elongated cells with oval nuclei which, however, retained their even distribution and their typical dense chromatin pattern (Fig. 5). The regular vascular pattern was very prominent owing to intense congestion of the capillaries. There was extensive necrosis, patchy in some areas, massive in others. The nuclei at the edges of the zones of necrosis were pyknotic and showed a tendency to pseudopalisading. Haemorrhages were prominent and occupied large areas of the tissue. Small calcospherites were scattered through the tumour.

The astrocytic part consisted predominantly of large, round or polygonal, gemistocytic cells with single or multiple nuclei arranged peripherally (Fig. 6). Glial fibres were sparse in the centre of the tumour but more abundant at the periphery. Typical and atypical mitotic figures were present. Multinucleated giant cells with hyperchromatic nuclei were scattered through the tumour. The demarcation from the oligodendroglial part was more abrupt than in twin 1 . There was prominent lymphocytic cuffing around the relatively sparse blood-vessels.

\section{DISCUSSION}

There seems no doubt that hereditary factors play an important part in the genesis of certain tumours of the nervous system. In von Recklinghausen's disease the occurrence of gliomas is well documented as well as of meningiomas and cranial nerve sheath tumours. There is evidence of a strong genetic factor in the occurrence of tuberous sclerosis, a disease in which gliomas not uncommonly occur. Familial

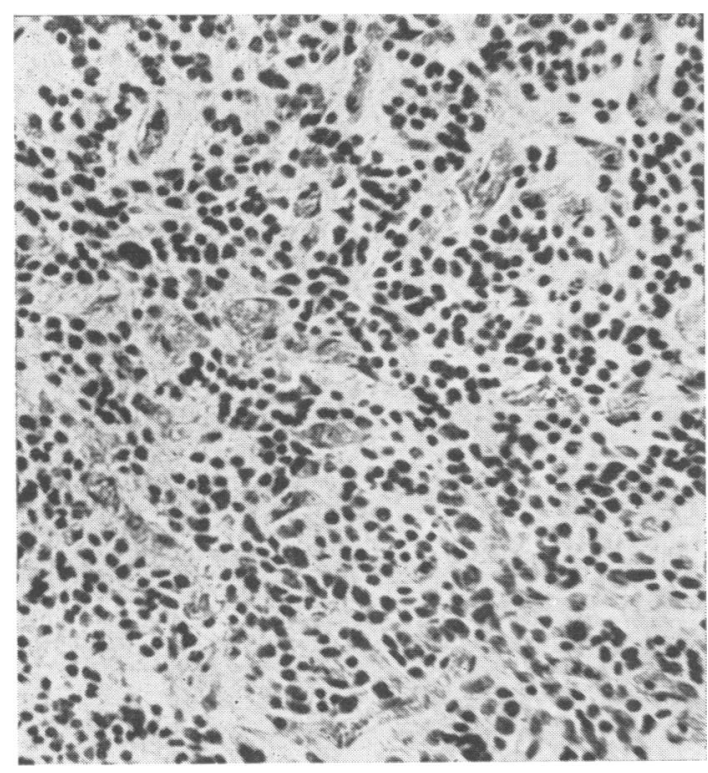

FIG. 5. Case 2. Oligodendroglial part of tumour consisting of typical small round cells. $H$ and $E, \times 240$.

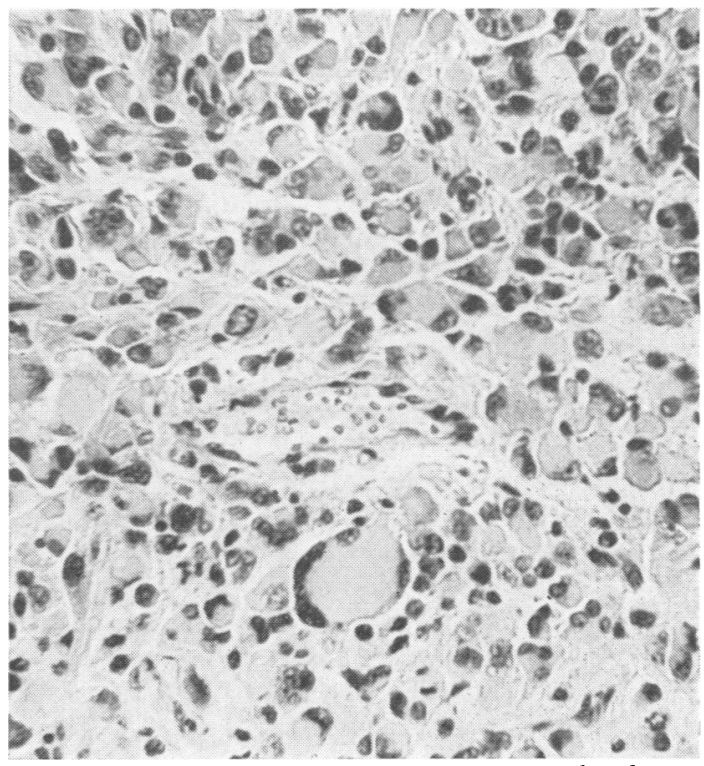

FIG. 6. Case 2. Part of tumour consisting mainly of gemistocytic astrocytes. $H$ and $E, \times 240$.

polyposis coli has recently been noted to be associated with cerebral tumours (Turcot, Després, and St. Pierre, 1959). Three fatal cases of glioblastoma multiforme have been described in siblings suffering from polyposis coli (Baughman, List, Williams, Muldoon, Segana, and Volkel, 1969). A fourth sibling of this family also died of a glioblastoma multiforme but the presence of polyposis coli was never proven.

Apart from these known genetically determined diseases there is comparatively little firm evidence that genetic factors play a part in the causation of gliomas. Two major statistical studies have been undertaken to try to establish whether the relations of patients with proven gliomas are more likely to suffer from this same disease than the general population. Harvald and Hauge (1956) studied 1,744 relatives of 169 patients with proven glioblastomas and compared them with a similar series of controls. They concluded that inherited factors play no major aetiological role in glioblastomas. In a larger series the same authors (Hauge and Harvald, 1957) carried out a similar study in a series of glioblastomas, medulloblastomas, and meningiomas, and again concluded that hereditary factors play scarcely any part in the aetiology of these tumours. However, van der Wiel (1960), in a similar investigation, studied 5,262 relatives of 100 patients with proven gliomas. He found that seven of these relatives had died of a verified glioma. Among the control group there were no cases of glioma. Van der Wiel con- 
cluded that the mortality from glioma was four times greater in the relatives of patients with proven gliomas than in the general population of the Netherlands.

The literature contains some 20 references to the occurrence of gliomas in blood relations. The subject is well reviewed by Koch (1954) and by Kjellin, Müller, and Åström (1960). It is difficult to assess the statistical significance of this relatively small number of cases.

Cases of glioma occurring in twins are even more rare. Joughin (1928) reported twin sisters who developed gliomas of the right and left cerebral hemispheres respectively. They both died of this disease within a period of two years. The histological nature of the gliomas is not recorded. Kjellin et al. (1960) reported twin brothers who both had astrocytomas of the right temporal lobe. The age of onset in one twin was 33 years and in the other 50 years.

There are three further references to cerebral tumours occurring in twins. Leavitt (1928) described twin boys of $6 \frac{1}{2}$ and $8 \frac{1}{2}$ years who both died of cerebral tumours. The younger was proven by operation to have a cerebellar medulloblastoma. The older had identical symptoms and signs but no operation was carried out and the precise nature of the tumour in this case was never established. Hoppe (1952) reported twin brothers one of whom was treated for a sphenoidal wing meningioma at the age of 40 and the other for a glioblastoma fusiforme at the age of 54. Griepentrog and Pauly (1957) described twin sisters of 8 and 11 weeks, one of whom had a cerebellar medulloblastoma and the other multiple cerebellar medulloblastomas with a teratoid tumour of the chest.

The twins we have described are, therefore, only the third pair of twins who are known to have developed gliomas of the brain. It is of interest that their tumours both manifested themselves during the first decade of life and ran similar clinical courses. The tumour in the cerebral hemisphere of the second twin was much larger than that in the hind-brain of the first and it may be argued that the latter manifested itself at an earlier age owing to its more strategically important situation. There is, however, nothing either in the clinical history or in the appearance of the tumour in the second twin to suggest that it was of long duration or slow growth.

The histological appearances of the two tumours were similar and differed only in detail. Both were mixed glial tumours consisting of oligodendroglial and astrocytic elements both of which showed evidence of anaplasia. The presence of a large number of bizarre cell forms in the first twin may well have been the result of irradiation. These tumours, although fairly characteristic of malignant gliomas of childhood are rare and account only for a small fraction of oligodendroglial tumours which as a group comprise between 5\% (Russell and Rubinstein, 1963) and $12.4 \%$ (Zülch, 1956) of all gliomas. The chance of such tumours arising in twins by coincidence seens so remote that one can hardly escape the conclusion that other factors, environmental or genetic, must have played a part in their causation. It may be added that a search for possible external factors, particularly during pregnancy, yielded negative results.

It is impossible to draw any valid conclusion on genetic influences from three pairs of gliomas in identical twins, particularly as the number of cases in which only one twin was affected is unknown. It seems therefore desirable that all cases of tumours in twins, whether affecting one or both, should be recorded in a central registry so that a sufficient body $\overrightarrow{\vec{\omega}}$ of evidence might accrue to throw further light on the role of genetics in the causation of these tumours.

Twin 1 was under the care of the late Mr. J. V. Crawford to whom we are indebted for his clinical records. We would like to thank Dr. C. O. Carter of the Institute of Child Health for his helpful advice on genetics. The wor $\bar{\phi}$ was supported by a grant from the Cancer Researc $\frac{\text { S }}{2}$ Campaign.

\section{REFERENCES}

Baughman, F. A. Jr., List, C. F., Williams, J. R., Muldoo+ J. P., Segarra, J. M., and Volkel, J. S. (1969). The gliom络 polyposis syndrome. New Engl.J. Med., 281, 1345-1346. 을 Griepentrog, F., and Pauly, H. (1957). Intra- und extrą- $\vec{v}$ kranielle, frühmanifeste Medulloblastome bei erbgleichen Zwillingen. Zbl. Neurochir., 17, 129-140.

Harvald, B., and Hauge, M. (1956). On the heredity of glioblastoma. J. nat. Cancer Inst., 17, 289-296.

Hauge, M., and Harvald, B. (1957). Genetics in intracranial tumours. Acta genet. (Basel), 7, 573-591.

Hoppe, H-J. (1952). Diskordantes Auftreten von Hirntu- 气 moren bei erbgleichen Zwillingen. Zbl. Neurochir., 12, ¿ 34-36.

Joughin, J. L. (1928). Coincident tumor of the brain in twins. Arch. Neurol. Psychiat. (Chic.), 19, 948-950.

Kjellin, K., Müller, R., and Åström, K. E. (1960). The occurrence of brain tumors in several members of a family. J. Neuropath. exp. Neurol., 19, 528-537.

Koch, G. (1954). Beitrag zur Erblichkeit der Hirngeschwülste. Acta Genet. med. (Roma), 3, 170-191.

Leavitt, F. H. (1928). Cerebellar tumors occurring in identical twins. Arch. Neurol. Psychiat. (Chic.), 19, 617-622.

Russell, D. S., and Rubinstein, L. J. (1963). Pathology of Tumours of the Nervous System, p. 127. 2nd edition. Arnold: London.

Turcot, J., Després, J.-P., and St. Pierre, F. (1959). Malignant tumors of the central nervous system associated with familial polyposis of the colon: report of two cases. Dis. Colon Rect., 2, 465-468.

Wiel, H. J. van der (1960). Inheritance of Glioma. Elsevier, Amsterdam.

Zülch, K. J. (1956). Biologie und Pathologie der Hirngeschwülste In Handbuch der Neurochirurgie, p. 178. Edited by $\mathbf{H}$. Olivecrona and W. Tönnis. Springer: Berlin. 